\title{
Andreas Schalhorn (dir.), Willi Baumeister. Der Zeichner
}

Hélène Ivanoff

\section{OpenEdition}

Journals

Édition électronique

URL : http://journals.openedition.org/ifha/9768

DOI : $10.4000 /$ ifha.9768

ISSN : 2198-8943

\section{Éditeur}

IFRA - Institut franco-allemand (sciences historiques et sociales)

\section{Référence électronique}

Hélène Ivanoff, « Andreas Schalhorn (dir.), Willi Baumeister. Der Zeichner», Revue de I'IFHA [En ligne], Date de recension, mis en ligne le 30 novembre 2018, consulté le 24 septembre 2020. URL : http:// journals.openedition.org/ifha/9768; DOI : https://doi.org/10.4000/ifha.9768

Ce document a été généré automatiquement le 24 septembre 2020.

(CIFHA 


\section{Andreas Schalhorn (dir.), Willi Baumeister. Der Zeichner}

Hélène Ivanoff

\section{RÉFÉRENCE}

Andreas Schalhorn (Hg.), Willi Baumeister. Der Zeichner. Figur und Abstraktion in der Kunst auf Papier, Berlin: Kupferstichkabinett der staatlichen Museen, 2018, 160 p., $34 €$ 
Édité par le conservateur du cabinet d'art graphique de Berlin Andreas Schalhorn, ce catalogue est paru à l'occasion d'une exposition rétrospective consacrée à l'œuvre de Willi Baumeister au Kultur Forum : «Willi Baumeister. Le dessinateur. Figure et abstraction dans l'art sur papier " (9 décembre 2017 - 8 avril 2018). Elle présentait environ 100 dessins et estampes de l'artiste, né à Stuttgart en 1889 et décédé dans la même ville en 1955.

Elle montrait comment Willi Baumeister fut durant toute sa vie engagé dans des réflexions liées au processus d'abstraction, sans pour autant renoncer à la figuration: des premières

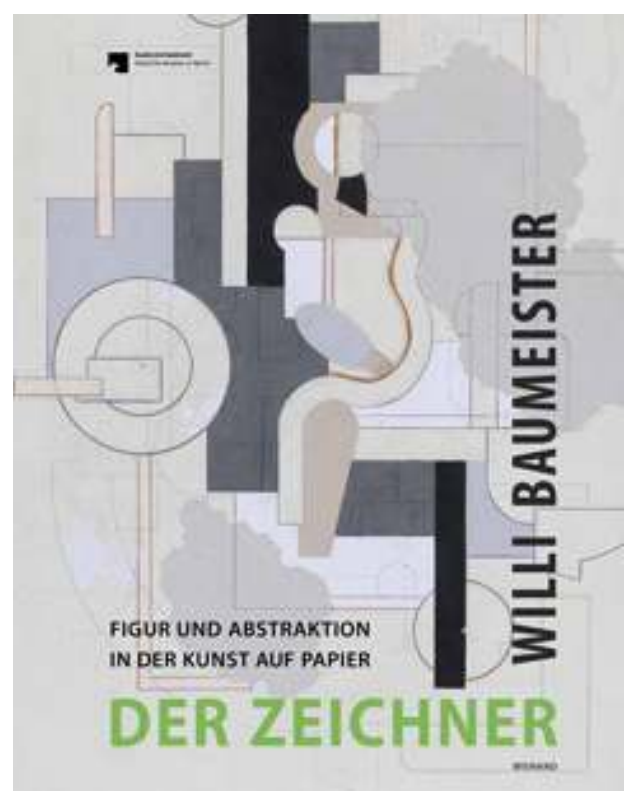
représentations géométriques des années 1920 , en passant par les formes organiques et les lignes fluides des années 1930, pour parvenir aux grandes tâches noires d'après 1945. Le livre met en exergue la place essentielle que jouait le dessin dans sa création artistique - technique qui, pour lui, ne se limitait pas à un travail préparatoire pour la peinture. L'artiste a en effet laissé environ 2000 œuvres sur papier dont l'exposition présentait une sélection.

Depuis la grande rétrospective organisée à la Galerie nationale de Berlin pour le centenaire de sa naissance en 1989 et celle présentée au Musée d'art de Stuttgart pour le $130^{\circ}$ anniversaire en 2014, c'est l'une des plus importantes expositions consacrées à l'artiste, dont les œuvres furent montrées à Paris par Jeanne Bucher (1872-1946) qui le considérait comme un "Picasso allemand». Il s'inscrivait dans la mouvance de différents courants artistiques: ami de Fernand Léger (1881-1955) et d'Amédée Ozenfant (1886-1966), admirateur de ses maîtres du Bauhaus comme Paul Klee (1879-1940) et Wassily Kandinsky (1886-1954), il était également proche d'Oskar Schlemmer (1888-1943) et des surréalistes, tel Max Ernst (1891-1976) ou Magritte (1898-1967).

Qu'il s'agisse des gouaches ou des dessins au crayon, cet art sur papier atteste de l'expérimentation de différents procédés par l'artiste, en particulier du collage et du frottage, et d'une œuvre extrêmement travaillée, laissant peu de place aux esquisses spontanées et à l'improvisation inconsciente, à laquelle d'autres artistes se consacraient à la même époque. En outre, la stigmatisation de sa création comme « art dégénéré » et l'interdiction d'enseigner l'ont probablement encouragé à développer une pensée théorique de l'abstraction, qu'il délivra dans son ouvrage d'esthétique paru en 1947 : «L'Inconnu dans l'art » (Das Unbekannte in der Kunst).

Adoptant un plan chronologique, le catalogue présente plusieurs essais d'Andreas Schalhorn, biographique ("Le dessinateur Willi Baumeister. Une introduction») et esthétique («De la figure construite à la figure biomorphique. Le dessin des années 1920 et 1930), puis un texte de Jenny Graser abordant le traitement de l'espace (« De la surface à la troisième dimension - l'illusion du relief dans les dessins de Baumeister »), suivie d'une analyse d'Andreas Schalhorn concernant le concept de temporalité 
("Archaïque et Présent. Le dessin des années 1940 et 1950 ») et enfin un essai de Catalina Heroven («Willi Baumeister en tant qu'imprimeur»). Romana Wojtynek établit quant à elle la chronologie.

Contrairement à d'autres recherches qui avaient choisi de se pencher sur une période définie comme les années francfortoises pour les 50 ans de sa mort (Manfred Großkinsky/Birgit Sander, Willi Baumeister : 1889 - 1955 ; die Frankfurter Jahre 1928 -1933, 2005) ou qui proposait l'analyse d'une thématique précise, telle les relations entre la préhistoire et l'œuvre de Baumeister (Wolfgang Schürle/Nicholas J. Conrad, Zwei Weltalter. Eiszeitkunst und die Bildwelt Willi Baumeisters, 2005), ce catalogue délivre une vision d'ensemble de l'œuvre sur papier, démontrant la cohérence des processus créateurs de l'artiste à la recherche d'un langage universel et l'approfondissement de ses réflexions sur la notion de formes entre figuration et abstraction.

\section{INDEX}

Index chronologique : Époque contemporaine

Thèmes : Histoire de l'art 